\title{
Effects of intensity of magnetic field generated by neodymium permanent magnet sheets on electrical characteristics of monocrystalline silicon solar cell
}

\author{
P. Panmuang, C. Photong \\ Solar Energy and Energy Resources Unit, Faculty of Engineering Mahasarakham University Khamriang District, \\ Mahasrakham, Thailand
}

\begin{abstract}
Article Info
Article history:

Received Jun 2, 2020

Revised Aug 3, 2020

Accepted Aug 18, 2020

\section{Keywords:}

Fill factor

Magnetic field intensity

Monocrystalline

Silicon solar cell

ABSTRACT

In this research, the effects of magnetic field intensity on electrical characteristics of a monocrystalline silicon solar cell were investigated. The experimental test-rig under Standard Test Condition was set up and tested to observe the respective effects. The electrical characteristics in terms of current-voltage-power curves, critical solar cell parameters and fill factor were then examined and analyzed. The outcome of this study demonstrates that the external magnetic field has a positive impact on electrical parameters, the experimental results showed that applying magnetic intensity of $60-260 \mathrm{mT}$ significantly affected the electrical characteristics of the cell; i.e., maximized cell current, voltage and power by $12.20,7.12$ and $23.60 \%$, respectively. In addition, this positive impact consequencely happened on the i-v and $\mathrm{p}-\mathrm{v}$ electrical characteristics curves of the solar cell; reflected by $3.69 \%$ increasing in the fill factor.
\end{abstract}

Solar cell characteristic curves

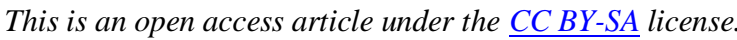

\section{Corresponding Author:}

Piyapat Panmaung

Solar Energy and Energy Resources Unit

Faculty of Engineering Mahasarakham University Khamriang District

Kantarawichai, Mahasrakham, Thailand, 44150

Email: piyapat.p@msu.ac.th

\section{INTRODUCTION}

Electricity that is directly produced from sunlight using a solar cell is DC [1]. Besides being able to convert sunlight to DC with good quality of output power, the cell is also required to have high energy conversion efficiency for maximum amount of generated power [2]. In fact, the best efficiency recorded for monocrystalline silicon solar cell (most attractive material and structure) is relatively low, being only $15-20 \%$ [3]. Therefore, a number of studies on solar cell efficiency enhancement have been carried out [4, 5], which can be classified into three common approaches. First, by using new or modified cell materials and structures, earth abundant absorbers, and innovative devices [6, 7]. This approach can enable more effective charge collection as well as better absorption of the solar spectrum that to be built inside the solar cells. Second, employing suitable peripheral elements or devices to improve the solar cell efficiency [8, 9]. Third, dealing with sophisticated environmental factor enhancement, e.g., reducing temperature on the cell's surface $[10,11]$. However, controlling environmental factors such as wind, dust, and mud would cause more complexity and excessive power consumption for the cell $[12,13]$.

Alternatively, in 2002, [14] proposed that electric fields could change the open-circuit voltage $\left(\mathrm{V}_{\text {oc }}\right)$ of the silicon Photovoltaic (PV) cells and subsequently several reports on the impact of magnetic fields on the solar cells, indicated similar results as with electric fields $[14,15]$; the details of these studies are as follows: 
The simulated test results from showed that an external magnetic field intensity of 0.003 to $0.079 \mathrm{~T}$ could linearly increase $\mathrm{V}_{\mathrm{oc}}$ of the $\mathrm{CdS} / \mathrm{CuInSe} 2$ solar cells. With similar effects, applying external magnetic field intensity (B) less than 10mT on the Ru-bipyridyl dye N719 or CdS-sensitized ZnO nanorods-based solar cells (DSCs) could increase the photocurrent of the cells by $25 \%$ and 34\%, respectively [14]. External B of $45 \mathrm{mT}$ could increase the short-circuit current of the dye-sensitized $\mathrm{TiO} 2$ nanoparticle-based solar cells (DSCs) by 13\% [16]. Magnetic field intensity B of $0-10 \mathrm{mT}$ could increase $\mathrm{V}_{\mathrm{oc}}$ and Fill Factor (FF; ratio of maximum power from the actual solar cell to the maximum power from the ideal solar cell; where the good cell has FF between 0.7 to 0.8 while the bad cell has 0.4 ) of the bifacial silicon solar cell from $653.89 \mathrm{mV}$ to $662.69-704.40 \mathrm{mV}$ and 0.83 to $0.83-0.84$, respectively [17]. These results were also supported by $\mathrm{M}$. Zoungrana et al., where applying an external B of $1-5 \mathrm{mT}$ could provide higher $\mathrm{V}_{\mathrm{oc}}$ (from $717 \mathrm{mV}$ to 721 $756 \mathrm{mV}$ ) and FF from 0.84 to $0.84-0.88$, respectively [18]. These results were similar to the research [19], where applying an external B of $15-50 \mathrm{mT}$ could increase $\mathrm{V}_{\text {oc }}$ (from $20 \mathrm{~V}$ to $20.5-21.5 \mathrm{~V}$ ) and $\mathrm{FF}(0.50$ to 0.53 0.59 ) on the silicon solar panel. Magnetic vinyl (B less than 0.05T) attachment to SJ Si-SC from the side of back electrode of single-junction (SJ) single-crystal silicon solar cells (Si-SC) with horizontal n+-p-p+ diode structure could increase of minority charge carriers lifetime and reduce recombination centers quantity in SJ $\mathrm{Si}$-SC. In the research [20], after storage of investigated objects on magnetic vinyl during three weeks their efficiency decrease quantity of recombination centers insignificantly, from $11.8-12.5$ to $11.5-12.2 \%$, in a difference from samples without attached magnetic vinyl, for which efficiency only for the first 7 days decrease up to $9.2-10.5 \%$.

The photoactive film was prepared under the application of a magnetic field perpendicular to the substrate during solvent drying process. The power conversion efficiency was improved up to $\sim 60 \%$ for the treated cell. The improved device performance can be attributed to the overall improvement of polymer crystallinity [21]. The photovoltaic performance of the perovskite solar cells using magnetic field to improve power conversion efficiency (PCE) was reported. The cell films with larger crystalline gain and longer carrier lifetimes had an average PCE of $17.84 \%$ and the highest PCE of $18.56 \%$ using an optimized magnetic field at $80 \mathrm{mT}$. In contrast, the PSCs fabricated without a magnetic field give an average PCE of $15.52 \%$ and the highest PCE of $16.72 \%$ [22]. The effect of a magnetic field on the photocurrent generated by a bulk heterojunction solar cell made from poly-3-hexylthiophene (P3HT) and [6,6]-phenyl C61-butyric acid methyl ester (PCBM) was investigated. At the operating voltage, 9\% increases in photocurrent of can be obtained at magnetic fields of less than $100 \mathrm{mT}$ [23]. Weak dc magnetic fields $(0.17 \mathrm{~T})$ increased the free carrier lifetime in Si wafers, which was thought to be convincing evidence of the metal impurity gettering effect. This processing was found to improve carrier lifetimes by up to a factor of 2, from about $3 \mu$ s to $7 \mu$ s in silicon wafers [24]. The effect of magnetic field on the photocurrent generation of organic solar cells, was investigated. In the case of bulk-heterojunction organic solar cell with the active layer made of P3HT:PCBM found that an increase of about $8 \%$ in the photocurrent density of the cell was observed when the intensity of the magnetic field reached $15 \mathrm{mT}$, and moreover, the increase in the photocurrent density saturated at about $9 \%$ when the magnetic fled was further intensified [25]. Over 50\% enhanced efficiency was observed from bulk heterojunction (BHJ) polymer solar cells (PSCs) incorporated with magnetic nanoparticles and an external magnetostatic field alignment when compared to the control BHJ PSCs. The optimization of BHJ thin film morphology, enhancement in charge carrier collection resulted in a greatly increased short-circuit current density, fill factor and power conversion efficiency [26].

However, most of the above mentioned research applied magnetic fields in parallel direction with respect to the surface of the p-n junction of the solar cell by simulation. In case of perpendicular direction, preparing solar cell films. In addition, the works proposed only the results that were obtained from point-topoint tests, while the whole $\mathrm{v}$-i-p characteristics curves of the cells have not been presented.

In this research, the direct application of external magnetic fields (perpendicular direction) to the most commonly used structure of monocrystalline silicon solar cell was examined and analyzed. The most effective B in theory [27] in the range of $0-260 \mathrm{mT}$ was used. The comprehensive $\mathrm{v}$-i-p characteristic curves and therefore the critical parameters: $\mathrm{V}_{\mathrm{oc}}, \mathrm{I}_{\mathrm{sc}}, \mathrm{V}_{\mathrm{mp}}, \mathrm{I}_{\mathrm{mp}}, \mathrm{P}_{\max }$ and FF could be determined based on both theoretical and experimental verifications. This paper is organized as follows: methodology in Section 2, experimental test-rig and test scenarios in Section 3, results, discussion in Section 4 and the conclusions in Section 5.

\section{METHODOLOGY}

Figure 1 presents a diagram of the components, curves and parameters used for verifying the proposed concept. There were 3 main components used for the experimental test-rig: a light source, a solar cell and a magnetic field source which were located in order as shown in the diagram. The light source generates light beams close to the solar spectrum under controlled standard test conditions (STC) of $25^{\circ} \mathrm{C}$,

Effects of intensity of magnetic field generated by neodymium permanent magnet sheets... (P. Panmuang) 
$1,000 \mathrm{~W} / \mathrm{m}^{2}$ and 1.5 Air Mass. The monocrystalline silicon solar cell was selected to be used in the investigation due to its simplest form of p-n junction (as well as being the most commonly used solar cell material). The commercial permanent magnetic sheets were managed to provide uniform magnetic field intensity in the range of $0-260 \mathrm{mT}$ by placing them underneath the solar cell to avoid shading on the top surface of the cell. Detailed specification and dimension for each component that was actually implemented in the experimental tests are proposed in Section 3.

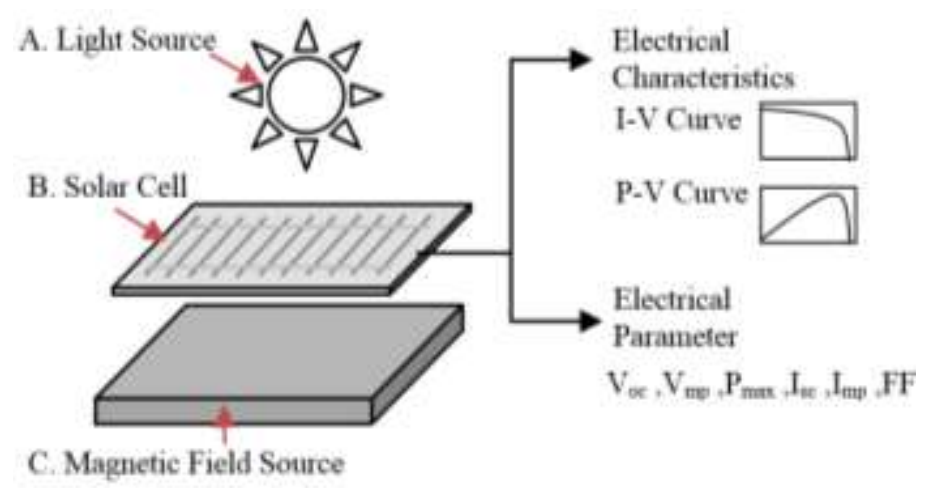

Figure 1. Diagram of the test concept in this research

\section{EXPERIMENT TEST-RIG AND TEST SCENARIOS}

\subsection{Light source}

As using sunlight would encounter problems of uncontrollable test conditions, a more flexible and reliable tungsten-halogen lamp with the light output spectrum [28] was used instead in this research. The irradiance level of 1 sun $\left(1,000 \mathrm{Watt} / \mathrm{m}^{2}\right.$; the intensity was measured by the solar power meter [29]) was achieved by placing the light $30 \mathrm{~cm}$ above the cell The $500 \mathrm{~W}$ halogen lamp [30] was installed inside the temperature and air control chamber to provide constant $25^{\circ} \mathrm{C}$ with almost air free condition (1.5 Airmass) solar meter, 500W halogen lamp and systems [31] as shown in Figure 2. The i-v-p curve tester model (Prova 200A) was used to measure the $\mathrm{i}-\mathrm{v}, \mathrm{p}-\mathrm{v}$ characteristics curves and critical parameters of the solar cell [32].

\subsection{Solar cell}

The monocrystalline silicon solar cell model c-si solar cell model SG 20184 [33] was used for this research due to its simplest p-n junction and structure, an because it is the most popular commercial cell. The structure consists of only one material type (c-si) but with different impurity (doping) rate on each side [34] as shown in Figure 3. The cell has the top surface area of 10.8 x $50 \mathrm{~mm}$ and thickness of $2 \mathrm{~mm}$ (size to fit with the magnetic sheet) and has $\mathrm{V}_{\mathrm{oc}}, \mathrm{I}_{\mathrm{sc}}$ and internal resistance of $6 \mathrm{~V}$, of $0.25 \mathrm{~A}$ and $1.3 \mathrm{ohms}$.

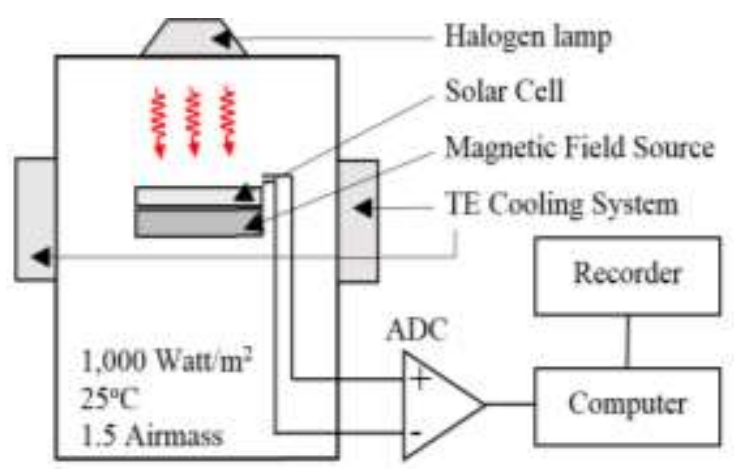

Figure 2. Illustrates the experimental arrangement of magnetic field effect on the solar cell irradiated by 500W Halogen lamp

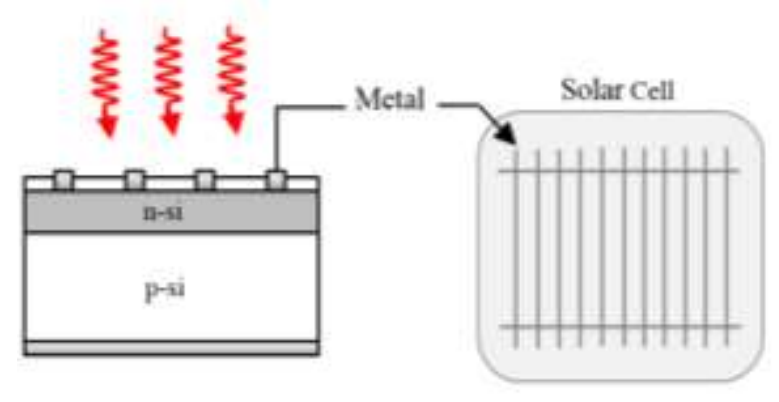

Figure 3. Basic structure of a monocrystalline silicon solar cell [35] 


\subsection{Magnetic field source}

To investigate the magnetic field influence on electrical characteristics of the silicon solar cell, external magnetic field intensities (B) of 0,60,160 and 260mT (the magnetic intensity was measured and tested by using GV-400A gauss meter for each particular testing permanent magnetic bar) were applied. A diagram of the test cell is shown in Figure 4. These B sources were generated from the Neodymium permanent magnet sheets with the same surface size of $100.2 \times 50 \mathrm{~mm}$ (fitted to the size of solar cell's surface) but having different thicknesses of 5, 10 and 20mm, as shown in Figure 5. In fact, the external B could affect the electrical characteristics of the cell in terms of photocurrent density $(\mathrm{J})$ as expressed by the equations of transportation phenomenon in (1)-(3):

$$
\begin{aligned}
& J_{b}(x)=q D_{n} \nabla \delta(x)+q \mu_{n} \delta(x) E(x) \\
& \nabla \times B=\mu_{o}\left(J+\varepsilon_{o}(\partial E) / \partial t\right) \\
& D_{n}=\mu_{n} k T / q=\tau_{n} k T / m_{e}
\end{aligned}
$$

Where:

$D_{n}$ is the electron's intrinsic diffusion coefficient

$\delta(x)$ is excess minority carrier density in the base $(\mathrm{g})$

$\hat{E}(x)$ is the electric field originating from carrier concentration gradient along the base $(\mathrm{g})$

$\mathrm{m}_{\mathrm{e}}$ is the electron mass

$T$ is the absolute temperature

$\tau_{n}$ is the charge carrier lifetime

The magnetic field helps to reduce electron-hole recombination rate for the silicon crystal, while increasing charge carrier lifetime $\tau_{n}[20,36,37]$ and thus consequently increasing $D_{n}$ [38] and electric voltage-current, respectively.

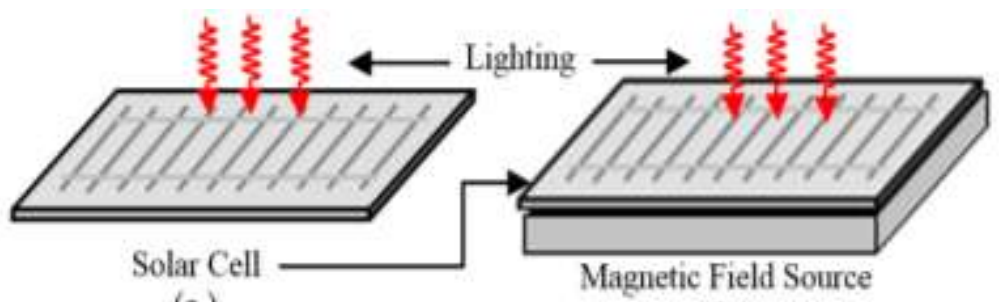

(a.)

(b.)

Figure 4. Diagram of the cell (a.) without and (b.) with magnetic field source

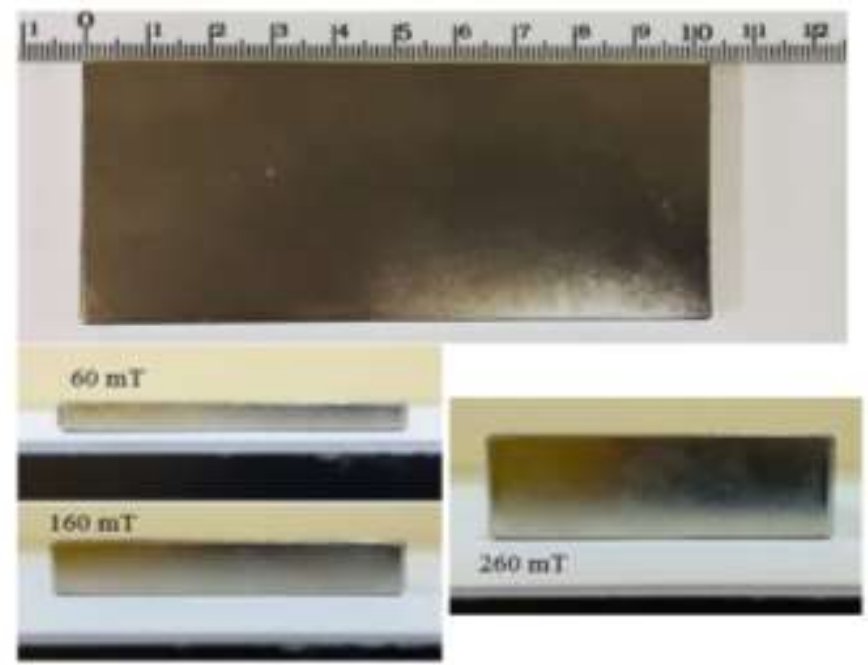

Figure 5. Photographs of the permanent magnet sheets used as magnetic field source in this research

Effects of intensity of magnetic field generated by neodymium permanent magnet sheets... (P. Panmuang) 


\subsection{Ambient temperature control}

In this research, the experimental test-rig utilized a closed chamber with the $\mathrm{w} \times 1 \times \mathrm{h}$ size of $40 \times$ $40 \times 60 \mathrm{~cm}$ to control the ambient temperature for the test components. A thermoelectric cooling (TEC) set based on the Peltier effect was used to control the ambient temperature inside the chamber to be within 25 $26^{\circ} \mathrm{C}$. The TEC set was mounted on the separated heatsink to dispose heat out of the chamber. The elements used for the aforementioned experiment test set-ups are shown in Figure 3.

\subsection{Solar module analyzer}

The solar module analyzer model Prova 200A [32] was used to measure the electrical characteristics curves and critical parameters of the solar cell; having the measurement capability as follow:

DC Voltage Measurement

Range, Resolution and Accuracy of Reading

$\left(0 \sim 10 \mathrm{~V}, 0.001 \mathrm{~V}\right.$ and $\pm 1 \% \pm\left(1 \%\right.$ of $\left.\left.\mathrm{V}_{\text {open }} \pm 9 \mathrm{mV}\right)\right)$

$\left(10 \sim 24 \mathrm{~V} 0.01 \mathrm{~V}, \pm 1 \% \pm\left(1 \%\right.\right.$ of $\left.\left.\mathrm{V}_{\text {open }} \pm 0.09 \mathrm{~V}\right)\right)$

DC Current Measurement

Range, Resolution and Accuracy of Reading

$\left(0 \sim 100 \mathrm{~mA}, 0.01 \mathrm{~mA}, \pm 1 \% \pm\left(1 \%\right.\right.$ of $\left.\left.\mathrm{I}_{\text {short }} \pm 0.09 \mathrm{~mA}\right)\right)$

$\left(100 \sim 600 \mathrm{~mA}, 0.1 \mathrm{~mA}, \pm 1 \% \pm\left(1 \%\right.\right.$ of $\left.\left.\mathrm{I}_{\text {short }} \pm 0.9 \mathrm{~mA}\right)\right)$

Electrical Specification $\left(23^{\circ} \mathrm{C} \pm 5^{\circ} \mathrm{C}\right)$, Internal Resistance at $\mathrm{I}_{\text {short }}$ : $0.05 \mathrm{Ohm}$.

\subsection{Experimental test scenarios}

The experimental test-rig was set up and tested. The results were used to compare the effects among B levels of $0,60,160$ and 260mT. The test scenarios are listed as follows:

a) Individual $\mathrm{i}-\mathrm{v}, \mathrm{p}-\mathrm{v}$ electrical characteristics curves for each particular testing $\mathrm{B}$ level

b) Average i-v, p-v electrical characteristics curves of each particular testing B level

c) Normalized values of the critical solar cell parameters: $\mathrm{V}_{\mathrm{oc}}, \mathrm{I}_{\mathrm{sc}}, \mathrm{V}_{\mathrm{mp}}, \mathrm{I}_{\mathrm{mp}}, \mathrm{P}_{\mathrm{max}}$ and FF.

\section{RESULTS AND DISCUSSION}

In this section, it is explained the results of research are organized as follows : The measured i-v, p-v electrical characteristics curves for each particular testing B level, The measured average i-v, p-v electrical characteristics curves of each particular testing B level and The normalized values of the critical solar cell parameters: $\mathrm{V}_{\mathrm{oc}}, \mathrm{I}_{\mathrm{sc}}, \mathrm{V}_{\mathrm{mp}}, \mathrm{I}_{\mathrm{mp}}, \mathrm{P}_{\mathrm{max}}$ and FF.

\subsection{The measured i-v, p-v electrical characteristics curves for each particular testing B level}

Figures 6 to 9 show the measured i-v electrical characteristics curves for each particular testing B level of $0,60,160$ and $260 \mathrm{mT}$ could provide $\operatorname{spread} \mathrm{I}_{\mathrm{sc}}(0.157-0.179 \mathrm{~A})$ and $\mathrm{V}_{\mathrm{oc}}(5.25-5.37 \mathrm{~V}), \mathrm{B}$ of $60 \mathrm{mT}$ could provide spread $\mathrm{I}_{\mathrm{sc}}(0.178-0.187 \mathrm{~A})$ and $\mathrm{V}_{\mathrm{oc}}(5.29-5.55 \mathrm{~V})$, B of $160 \mathrm{mT}$ could provide spread $\mathrm{I}_{\mathrm{sc}}(0.187-0.198 \mathrm{~A})$ and $\mathrm{V}_{\mathrm{oc}}$ $(5.34-5.72 \mathrm{~V})$ and $\mathrm{B}$ of $260 \mathrm{mT}$ could provide spread $\mathrm{I}_{\mathrm{sc}}(0.188-0.213 \mathrm{~A})$ and $\mathrm{V}_{\mathrm{oc}}(5.56-5.82 \mathrm{~V})$. Figures 10 to 13 shows the measured p-v electrical characteristics curves for each particular testing B level of 0, 60, 160 and 260 $\mathrm{mT}$ could provide spread $\mathrm{P}_{\max }(639-669 \mathrm{~mW}),(665-720 \mathrm{~mW}),(718-776 \mathrm{~mW})$ and $(782-844 \mathrm{~mW})$ respectively.

The obtained results showed that applying magnetic fields on the solar cell could improve the electrical $\mathrm{i}-\mathrm{v}$ and $\mathrm{p}-\mathrm{v}$ characteristic curves of the cell along the increasing rate of the magnetic fields intensity range under the study. However, larger variation in measured values of electrical parameters could be noticeable for higher magnetic intensity.

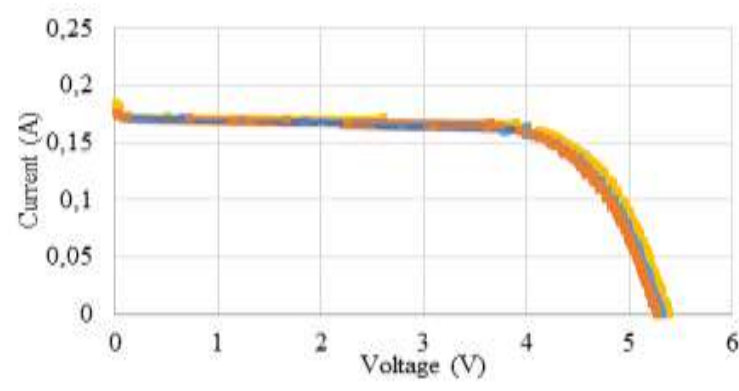

Figure 6. I-V electrical characteristic curves, 5 tests and case B:0 mT

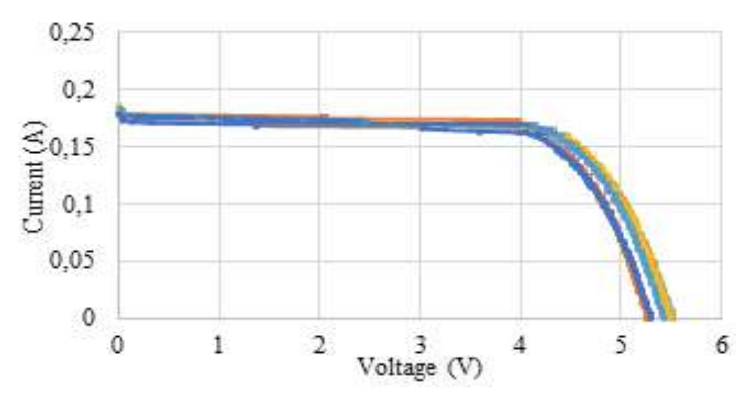

Figure 7. I-V electrical characteristic curves, case B: $60 \mathrm{mT}$ 


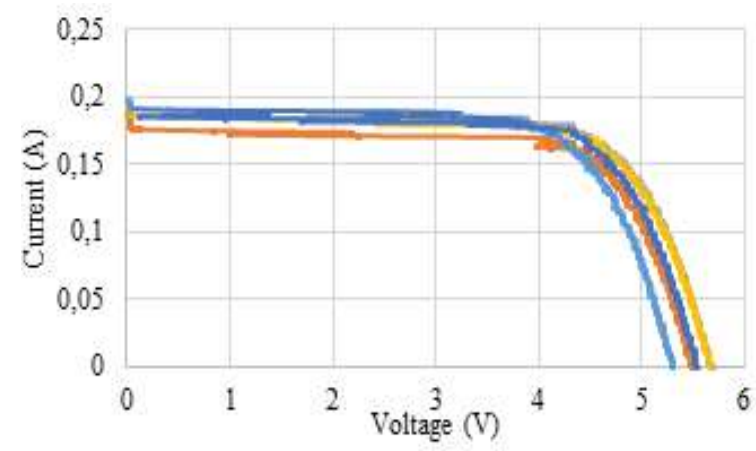

Figure 8. I-V electrical characteristic curves, 5 tests and case B: $160 \mathrm{mT}$

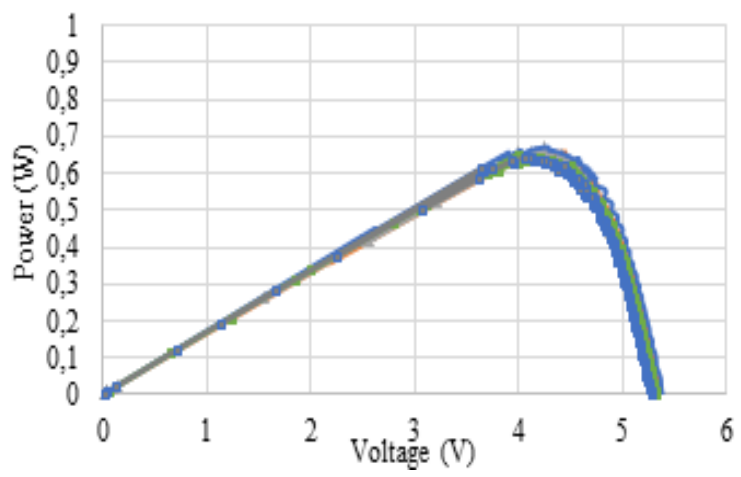

Figure 10. P-V electrical characteristic curves, 5 tests and case B: $0 \mathrm{mT}$

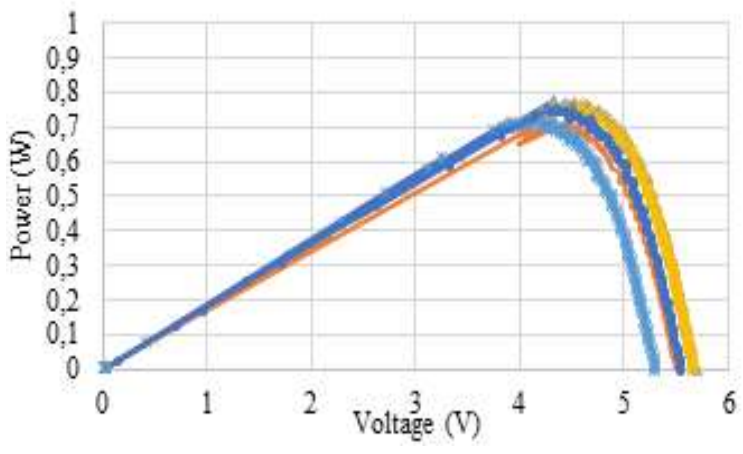

Figure 12. P-V electrical characteristic curves, 5 tests and case B: $160 \mathrm{mT}$

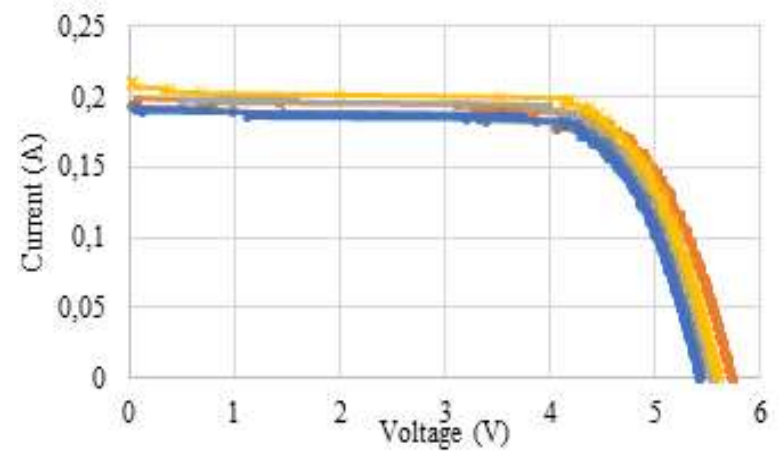

Figure 9. I-V electrical characteristic curves, 5 tests and case B: $260 \mathrm{mT}$

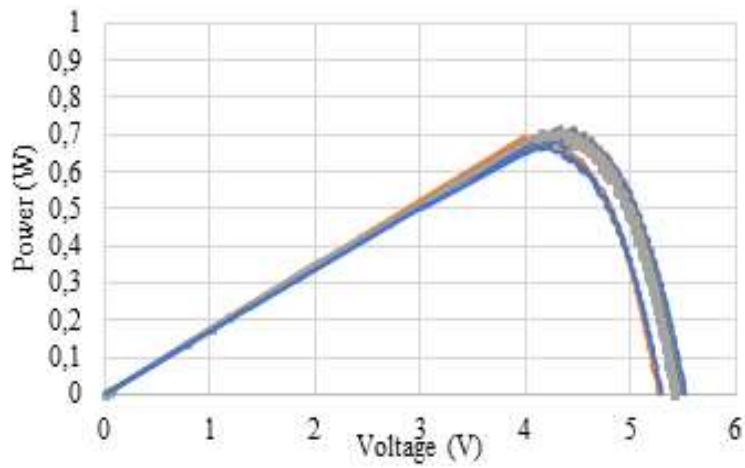

Figure 11. P-V electrical characteristic curves, 5 tests and case B: $60 \mathrm{mT}$

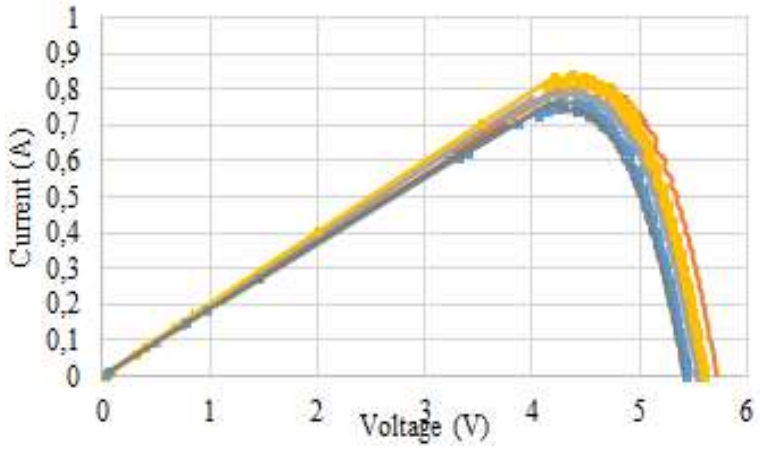

Figure 13. P-V electrical characteristic of cell, 5 tests and case B: $260 \mathrm{mT}$

\subsection{The measured average $i-v$, $p-v$ electrical characteristics curves of each particular testing $B$ level}

Figure 14 shows the measured average i-v electrical characteristics curve of each particular testing B level, where applying external B of 60160 and 260mT could provide higher curve profile than with applied $\mathrm{B}$ of 0mT. Figure 15 shows the measured average $\mathrm{p}-\mathrm{v}$ electrical characteristics curve of each particular testing B level, where applying external B of 60160 and 260mT could provide higher curve profile than case applied B of 0mT. 


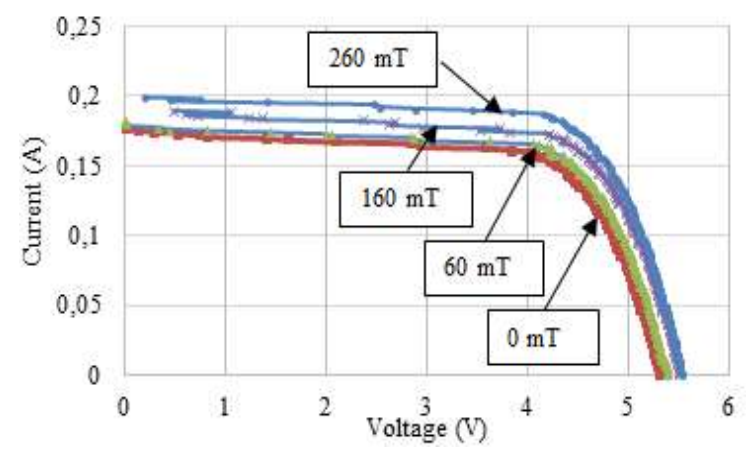

Figure 14. Average i-v electrical characteristic curves, case B: $060160260 \mathrm{mT}$

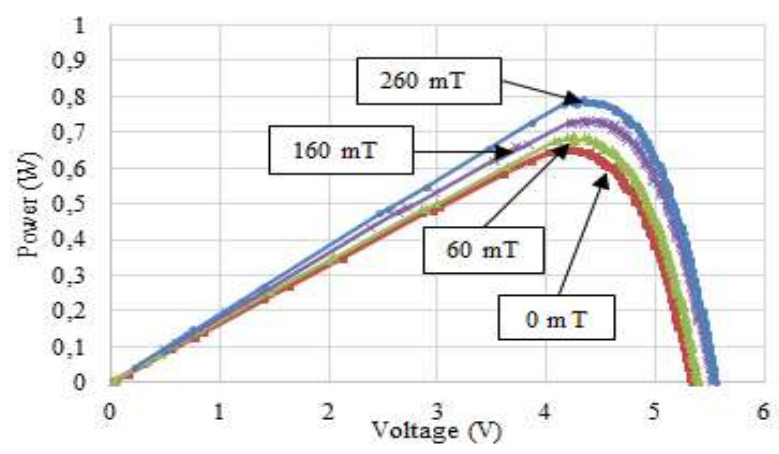

Figure 15. Average p-v electrical characteristic curves, case B: $060160260 \mathrm{mT}$

\subsection{The normalized values of the critical solar cell parameters: $V_{o c}, I_{s c}, V_{m p}, I_{m p}, P_{\max }$ and $F F$}

The experimental results shown in Figures 16 to 21 where applying external B of $0-260 \mathrm{mT}$ could provide higher $\mathrm{V}_{\mathrm{oc}}$ (from $5.29 \mathrm{~V}$ to $5.41-5.67 \mathrm{mV}$ ), $\mathrm{V}_{\mathrm{mp}}$ (from $4.13 \mathrm{~V}$ to $4.18-4.43 \mathrm{mV}$ ), $\mathrm{I}_{\mathrm{sc}}$ (from $177 \mathrm{~mA}$ to $182-199 \mathrm{~mA}$ ), $\mathrm{I}_{\max }$ (from $156 \mathrm{~mA}$ to $166-181 \mathrm{~mA}$ ), $\mathrm{P}_{\max }$ (from $650 \mathrm{~mW}$ to $694-804 \mathrm{~mW}$ ) and FF (from 0.69 to 0.7-0.72). The results of this section showed that the electrical parameters, $\mathrm{V}_{\mathrm{oc}}, \mathrm{V}_{\mathrm{mp}}, \mathrm{I}_{\mathrm{sc}}, \mathrm{I}_{\mathrm{mp}}, \mathrm{P}_{\max }$ and fill factor were improved for the treated cell with higher in values and thus increased the electricity generation performance and efficiency for the solar cell in overall.

The above explanation would be clearly shown by Figures 22-27; where applying the external B of 0-260 mT could provide higher values of $\mathrm{V}_{\mathrm{oc}}(1.02-1.07 \%), \mathrm{V}_{\mathrm{mp}}(1.02-1.07 \%), \mathrm{I}_{\mathrm{sc}}(1.02-1.12 \%), \mathrm{I}_{\max }$ $(1.05-1.15 \%), \mathrm{P}_{\max }(1.06-1.23 \%)$ and $\mathrm{FF}(1.01-1.03 \%)$.

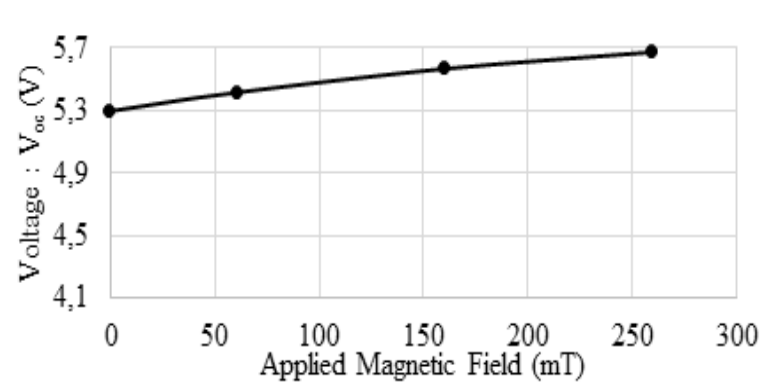

Figure 16. Open circuit voltage value $\left(\mathrm{V}_{\text {oc }}\right)$ of each testing B level

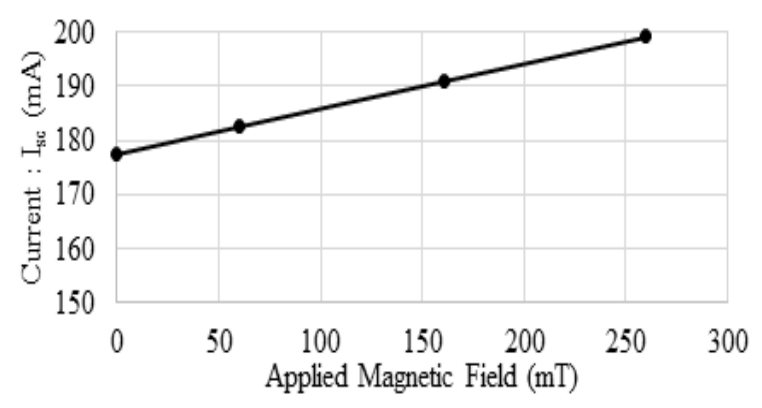

Figure 18. Short circuit current value $\left(\mathrm{I}_{\mathrm{sc}}\right)$ of each testing B level

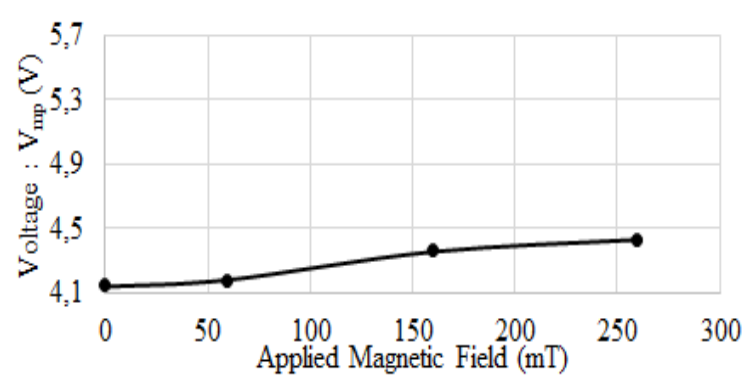

Figure 17. Maximum power voltage value $\left(\mathrm{V}_{\mathrm{mp}}\right)$ of each testing B level

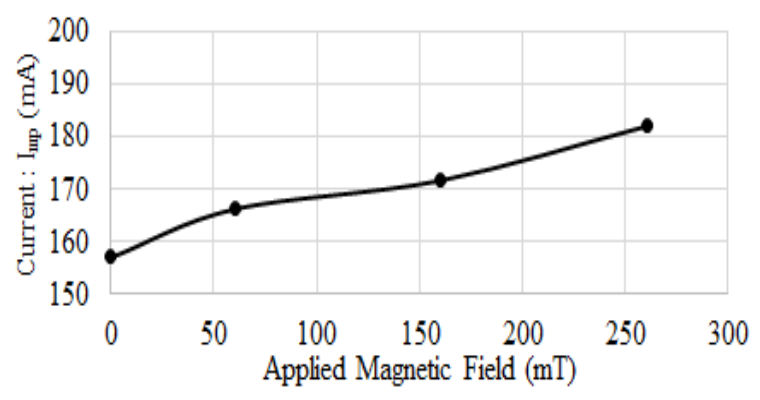

Figure 19. Maximum power current value $\left(\mathrm{I}_{\mathrm{mp}}\right)$ of each testing B level 


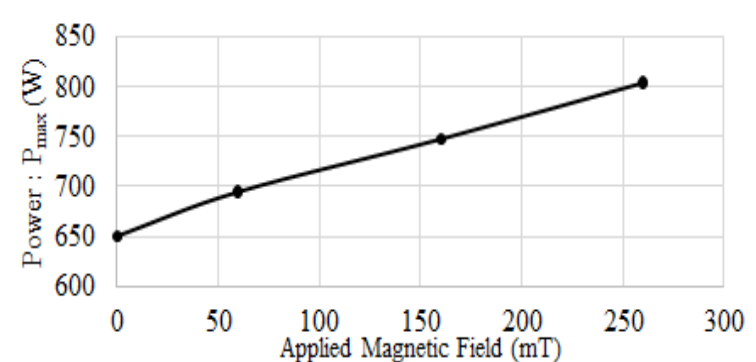

Figure 20. Maximum power value (Pmax) of each testing B level

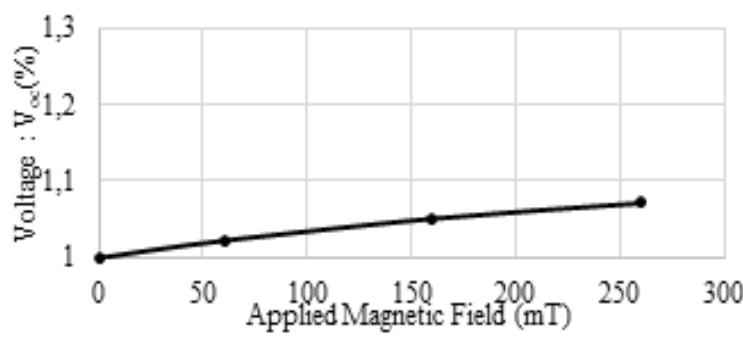

Figure 22. Normalized open circuit voltage value of each testing B level

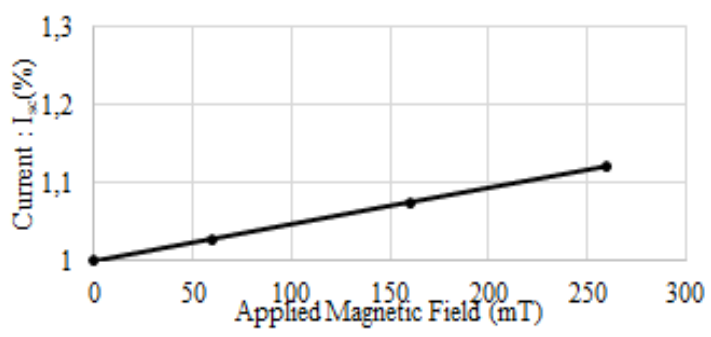

Figure 24. Normalized short circuit current value of each testing B level

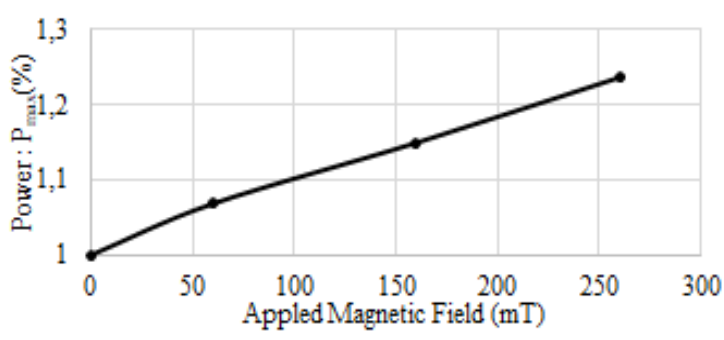

Figure 26. Normalized maximum power value of each testing B level

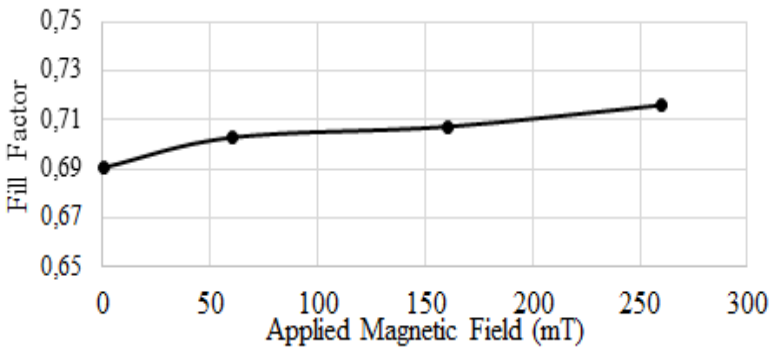

Figure 21. Fill Factor (FF) of each testing B level

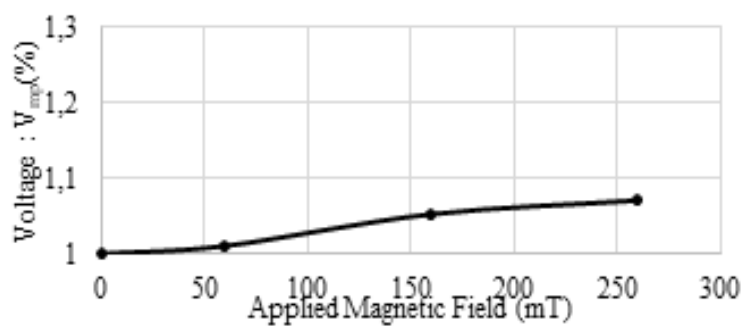

Figure 23. Normalized maximum power voltage value of each testing $B$ level

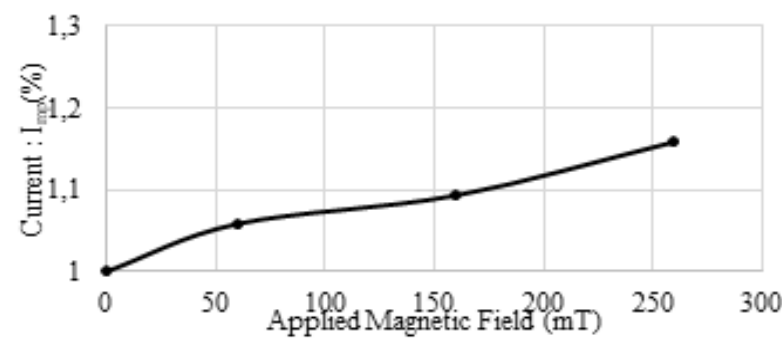

Figure 25. Normalized maximum power current value of each testing B level

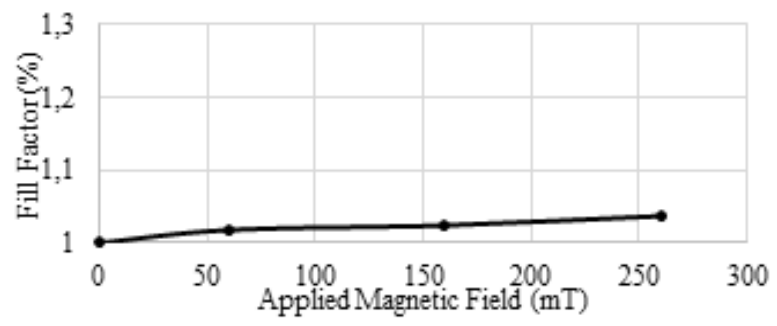

Figure 27. Normalized fill factor of each testing B level

\section{CONCLUSION}

The effects of magnetic field intensity on electrical characteristics of a monocrystalline silicon solar cell were presented. The experimental test-rig under standard test condition was set up and tested to observe the respective effects. The electrical characteristics in terms of current-voltage-power curves, critical solar cell parameters and fill factor were then examined and analyzed. The experimental results showed that 
applying magnetic intensity of 60-260mT significantly improved electrical characteristics curves, as well as, providing higher Voc (1.02-1.07\%), Vmp (1.02-1.07\%), Isc (1.02-1.12\%), Imax (1.05-1.15\%), Pmax $(1.06-1.23 \%)$ and FF (1.01-1.03\%).

\section{ACKNOWLEDGEMENTS}

The authors would like to express gratitude to Faculty of Engineering, Mahasarakham University for their financial support and for providing us with an opportunity to pursue this work. This research did not receive any specific grant from funding agencies in the public, commercial, or not-for-profit sectors.

\section{REFERENCES}

[1] C.Photong, "A comparison of three-phase grid-tied photovoltaic converters based on current fed configurations," IECON 2013-39th Annual Conference of the IEEE Industrial Electronics Society, Nov. 2013

[2] T. Kita, Y. Harada, and S. Asahi, "The Conversion Efficiency of a Solar Cell as Determined by the Detailed Balance Model," Green Energy and Technology, pp. 55-79, 2019.

[3] Bhalchandra V.Chikate, "The factors affecting the performance of solar cell," ICQUEST2015 - 4th International Conference on Quality Up-gradation in Engineering, Science and Technology, April. 2015.

[4] H. Fathabadi, "Effect of External AC Electric and Magnetic Fields on the Power Production of a Silicon Solar Cell," IEEE Journal of Photovoltaics, vol. 8, no. 6, pp. 1408-1412, Nov. 2018

[5] B. Sopori and D. J. Friedman, "Improving Silicon Solar Cell Efficiency Through Advanced Cell Processing, Highly Uniform Texturing, and Thinner Cells," Feb. 2019.

[6] F. Nicola and L. Rodino, "Background meterial," Global Pseudo-Differential Calculus on Euclidean Spaces, pp. 9$14,2010$.

[7] M. Dharmadasa, "Background of the CdTe Solar Cell and the New Device Concept," Advances in Thin-Film Solar Cells, pp. 71-114, Sep. 2018.

[8] U. Rau, "How the Optical Properties of a Solar Cell Influence its Performance - From the Efficiency Limits to Real Devices," Light, Energy and the Environment, 2016.

[9] N. Ekins-Daukes, I. Ballard, and K. Barnham, "Solar Cell Efficiency Enhancement and Revised Shockley-Queisser Limit for Low Dimensional Absorbers," Materials Research Society Symposium Proceedings, 2008.

[10] T. Mohammad and V. Dutta, "Effect of substrate temperature on spray coated PEDOT:PSS thin film morphology for organic solar cell," 2019.

[11] "Effect of temperature on photovoltaic solar energy conversion," Solar Energy, vol. 5, no. 4, p. 145, Oct. 1961.

[12] S. P. Aly, S. Ahzi, and N. Barth, "Effect of physical and environmental factors on the performance of a photovoltaic panel,” Solar Energy Materials and Solar Cells, vol. 200, p. 109948, Sep. 2019.

[13] "Effect of Different Environmental Factors on Performance of Solar Panel," Regular Issue, vol. 8, no. 11, pp. 1518, Sep. 2019.

[14] S. Erel, "The effect of electric and magnetic fields on the operation of a photovoltaic cell," Solar Energy Materials and Solar Cells, vol. 71, no. 2, pp. 273-280, Feb. 2002.

[15] S. Oviedo-Casado, A. Urbina, and J. Prior, "Magnetic field enhancement of organic photovoltaic cells performance," Scientific Reports, vol. 7, no. 1, Jun. 2017.

[16] F. Cai, S. Zhang, S. Zhou, and Z. Yuan, "Magnetic-field enhanced photovoltaic performance of dye-sensitized TiO2 nanoparticle-based solar cells," Chemical Physics Letters, vol. 591, pp. 166-169, Jan. 2014.

[17] Zerbo, M. Zoungrana, I. Sourabié, A. Ouedraogo, B. Zouma, and D. J. Bathiebo, "External Magnetic Field Effect on Bifacial Silicon Solar Cell's Electrical Parameters," Energy and Power Engineering, vol. 08, no. 03, pp. 146$151,2016$.

[18] M. Zoungrana, I. Zerbo, B. Soro, M. Savadogo, S. Tiedrebeogo, D. J. Bathiebo. "The effect of magnetic field on the efficiency of a silicon solar cell under an intense light concentration," Advances in Science and Technology Research Journal, vol. 11, no. 2, pp. 133-138, Jun. 2017.

[19] D. U. Combari, E. W. Ramde, I. Sourabie, M. Zoungrana, I. Zerbo, and D. J. Bathiebo, "Performance Investigation of a Silicon Photovoltaic Module under the Influence of a Magnetic Field," Advances in Condensed Matter Physics, vol. 2018, pp. 1-8, Nov. 2018.

[20] Zaitsev, R.V.. (2015). Cost-effective Silicon Solar Cells Efficiency Increase by the Magnetic Field Treatment. Journal of Nano- and Electronic Physics. 7. 1-4.

[21] F.-C. Hsu, C.-T. Chen, C.-H. Li, C.-C. Chen, and Y.-F. Chen, "The application of a magnetic field to improve polymer: Fullerence solar cell performance," 2014 IEEE 40th Photovoltaic Specialist Conference (PVSC), Jun. 2014.

[22] H. Wang, J. Lei, F. Gao, Z. Yang, D. Yang, J. Jiang, J. Li, X. Hu, X. Ren, B. Liu, J. Liu, H. Lei, Z. Liu, and S. (Frank) Liu, "Magnetic Field-Assisted Perovskite Film Preparation for Enhanced Performance of Solar Cells," ACS Applied Materials \& Interfaces, vol. 9, no. 26, pp. 21756-21762, Jun. 2017.

[23] P. Shakya, P. Desai, T. Kreouzis, W. P. Gillin, S. M. Tuladhar, A. M. Ballantyne, and J. Nelson, "The effect of applied magnetic field on photocurrent generation in poly-3-hexylthiophene:[6,6]-phenyl C61-butyric acid methyl ester photovoltaic devices, "Journal of Physics: Condensed Matter, vol. 20, no. 45, p. 452203, Oct. 2008. 
[24] Kuryliuk, L. Steblenko, A. Nadtochiy, and O. Korotchenkov, "Lifetime improvement in silicon wafers using weak magnetic fields," Materials Science in Semiconductor Processing, vol. 66, pp. 99-104, Aug. 2017.

[25] H. Fathabadi, "Comparative study on the effect of magnetic field on the photocurrent density of organic, dyesensitized and silicon solar cells," Journal of Materials Science: Materials in Electronics, vol. 30, no. 18, pp. 17314-17321, Aug. 2019.

[26] K. Wang, C. Yi, C. Liu, X. Hu, S. Chuang, and X. Gong, "Effects of Magnetic Nanoparticles and External Magnetostatic Field on the Bulk Heterojunction Polymer Solar Cells," Scientific Reports, vol. 5, no. 1, Mar. 2015.

[27] O. O. Korotchenkov, "Magnetic field-stimulated change of photovoltage in solar silicon crystals," Semiconductor Physics Quantum Electronics and Optoelectronics, vol. 16, no. 1, pp. 72-75, Feb. 2013.

[28] Soetedjo, Y. I. Nakhoda, A. Lomi, and T. A. Suryanto, "Solar Simulator Using Halogen Lamp for PV Research," Lecture Notes in Electrical Engineering, pp. 239-245, 2016.

[29] Solar power meter, by TENMARS. [Online]. Available: https://www.voake.com/product/tenmars-tm-206/

[30] $500 \mathrm{~W}$ Halogen, by Markpro Lighting. [Online]. Available: https://markprolighting.com/shop-2/floodlightseries/halogen/floodlight-tungsten-halogen-500w-r7s/

[31] Soetedjo, Aryuanto \& Nakhoda, Yusuf \& Lomi, Abraham \& Suryanto, Teguh. (2016). Solar Simulator Using Halogen Lamp for PV Research. 10.1007/978-981-287-988-2_25.

[32] Solar module analyzer, by TES Electrical Electronic Corp. [Online]. Available: http://www.tes.com.tw/en/product_detail.asp?seq=286

[33] Monocrystalline silicon solar cell. [Online]. Available: https://www.arduitronics.com/category/56/sensorsmodules/solar-cell

[34] "Silicon Solar Cell Material and Technology," Photovoltaic Solar Energy Generation, pp. 23-41.

[35] C. R. Wronski and N. Wyrsch, "Silicon Solar Cells silicon solar cell, Thin-film silicon solar cell thin-film," Solar Energy, pp. 270-322, 2013.

[36] Morales-Acevedo, "Effective absorption coefficient for graded band-gap semiconductors and the expected photocurrent density in solar cells," Solar Energy Materials and Solar Cells, vol. 93, no. 1, pp. 41-44, Jan. 2009.

[37] Kuryliuk, L. Steblenko, A. Nadtochiy, and O. Korotchenkov, "Lifetime improvement in silicon wafers using weak magnetic fields," Materials Science in Semiconductor Processing, vol. 66, pp. 99-104, Aug. 2017

[38] S. M. Sze, Semiconductor Device: Physics and Technology, 2nd ed. New York: Wiley, 2002.D. Buddhasukh, J. R. Cannon, B. W. Metcalf and A. J. Power, "Synthesis of 5-n-alkylresorcinol dimethyl ethers and related compounds via substituted thiophens”, Aust. J. Chem., 1971, 24, 2655-2664. (Apply M_Refer style).

\section{BIOGRAPHIES OF AUTHORS}

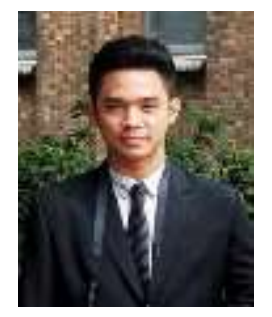

Piyapat Panmuang was born in Khonkaen province Thailand in 1989. He received his bachelor degree in Electrical Engineering from Khon Kaen University, Thailand and his master degree in Electrical and Computer Engineering from Mahasarakham University, Thailand. He is currently a lecturer at the Faculty of Engineering, Mahasarakham University, Thailand. His research interest includes thermoelectric, solar energy, renewable energy conversion and power electronics.

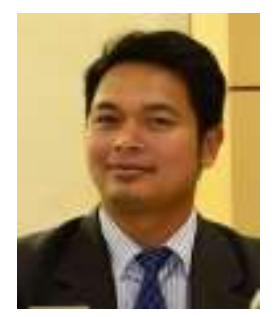

Chonlatee Photong was born in Maha Sarakham, Thailand in 1979. He received his bachelor degree in Electrical Engineering from Khon Kaen University, Thailand in 2001. He worked as a R\&D and maintenance engineer at Sony Device Technology (Thailand) Co., Ltd and Seagate Technology (Thailand) Co., Ltd. during 2001-2006. He received his M.Sc. in Power Electronics and Drives and his Ph.D. in Electrical and Electronic Engineering from the University of Nottingham, UK in 2007 and 2013, respectively. He has worked as a lecturer in power electronics at Mahasarakham University, Thailand since 2013-present. His research interest includes power electronics for solar, wind and other renewable energy conversions and applications. 